\title{
KẾT QUẢ ÚNG DỤNG PHẪU THUẬT NỘI SOI LỒNG NGỰC CẮT BỎ U TUYẾN ỬC ĐIỀU TRI BỆNH NHƯợC CƠ TẠI BỆNH VIỆN 103
}

Mai Văn Viện, Lê Việt Anh

\section{TÓMTÄT}

Mục tiêu: Đánh giá kết quả ứng dụng phẫu thuật nội soi lồng ngục trong cắt u tuyến ức điều trị bệnh nhurơc co

Đối tương và phương pháp: Nghiên cứu mô tả cắt ngang ở 38 bệnh nhân nhược cơ có u tuyến iúc trong số 68 truờng hợp được phẫu thuật nội soi cắt tuyến ức Tại Bệnh viện 103, tù̀ tháng 9/2008- 6/2012.

Kết quả: 38 bệnh nhân nhược co có u tuyến ức được phẫu thuật nọi soi lồng ngục: 26 nũ, 12 nam, tuổi trung bình 33,5 (12- 69). tình trạng nhược co: nhóm I: 4, IIA: 24, IIB:10. Giai đoạn u theo phân loại của Masaoka: I là 16, II là 14, III là 4 và IV là 4

Không có tử vong do phẫu thuật, tai biến 5,2\%, biến chứng 7,8\%, thời gian theo dõi hồi sưc tích cực trung bình 24giò̀ (1-72), số ngày điều trị trung bình sau mổ: 7,5 (5-20).

Kết quả tốt ở giai đoạn sớm (duơoi 1 năm) là 84,0\%, sau 1 năm 88,9\% tuoong đương tỷ lệ tốt 85,7\% và $88,7 \%$ của phuơng pháp cắt u tuyến ức bằng mổ mở đường giũ̃a xương ức hay mở ngục.

Kết luận: Phẫu thuật nội soi lồng ngực có thể áp dụng cắt tuyến úc nói chung, u tuyến úc nói riêng để điều trị bệnh nhược co;, không có tư vong phẫu thuật, tai biến, biến chứng thấp. Kết quả tốt ở giai đoạn sớm sau mổ tương đurong phẫu thuật mổ mở qua xưong ức.

Tù khoá: Phẫu thuật nội soi lồng ngực, Bệnh nhược co và u tuyến ức.

\section{EVALUTION RESULTS OF THORACOSCOPIC SURGERY IN THYMOMECTOMY FOR MYASTHENIA GRAVIS}

\section{Mai Van Vien, Le Viet Anh}

Objectives: To evaluate the results of thoracoscopic thymomectomy for Myasthenia Gravis at Hospital 103

Materials and methods: Cross-sectional descriptive study on 38 cases of thymoma among 68 patients with myasthenia gravis who were undergone thoracoscopic thymectomy at Hospital 103, from 9/2008 to $6 / 2012$

Results: There were $\mathbf{3 8}$ patients Myasthenia gravis with thymoma who was undergone thoracoscopic thymomectomy: 26 females, 12 males, mean age was 33,5 (range, 12-69), classification of Myasthenia was: stage I: (4), IIA:(24), IIB:(10). Masaoka's stages: I (16), II (14), III ( 4) and IV (4)

No hospital mortality, accidents $5,2 \%$, complications:7,8\%, mean time of intensive treatment was $24 h$ (1-72h), mean time of postoperative treatment 7,5 days (5-20). Early operative results show an equivalent effectiveness to the method of transternal thymectomy.

Conclusion: Thoracoscopic surgery can be widely indicated for patients with myasthenia gravis at stage I-IIB with or without thymoma.

Key words: Thoracoscopic surgery, Myasthenia gravis with thymoma

\section{1. ĐẶT VẤN ĐỀ}

Có khoảng gần một nửa số bệnh nhân nhược cơ có u tuyến ức. Việc cắt bỏ u tuyến ức nói riêng, tuyến ức nói chung từ lâu đã là một biện pháp điều trị hiệu quả bệnh nhược cơ.[1],[3].

Nếu như trước đây việc cắt bỏ tuyến ức, u tuyến ức thường được thực hiện bằng đường mở dọc giữa xương ức, thì ngày nay với sự phát triển của phẫu thuật nội soi lồng ngực việc cắt bỏ tuyến ức, $\mathrm{u}$ tuyến ức đã dần được thực hiện bằng phẫu thuật nội soi lồng ngực. [1],[2],[3],[6].

Tuy nhiên, cho tới nay trên thế giới cũng như trong nước việc ứng dụng phẫu thuật lồng ngực trong cắt bỏ u tuyến ức để điều trị bệnh nhược cơ chưa nhiều và chưa được quan tâm một cách thích đáng.

Tại Khoa Phẫu thuật Lồng ngực Bệnh viện 103, từ tháng 9/2008 đến 6/2012 điều trị ngoại khoa bệnh nhược cơ bằng cắt bỏ tuyến ức, $\mathrm{u}$ tuyến ức đã hầu như được thay thể bằng phẫu thuật nội soi lồng ngực [3],[4].

Mục tiêu của nghiên cứu này nhằm: Đánh giá kết quả ưng dụng phẫu thuật nội soi lồng ngục trong cắt bỏ u tuyến ức điều trị bệnh nhược co.

\footnotetext{
* Bộ môn - Khoa phẫu thuật lồng ngục - Bệnh viện 103, Học viện Quân $Y$

Người chịu trách nhiệm khoa họ: PGS.TS Mai Văn Viện Email: maivanvien103@gmail.com

Ngày nhận bài: 07/06/2013 - Ngày Cho Phép Đăng: 13/6/2013 Phản Biện Khoa hoc: GS.TS. Đặng Hanh Đệ,

PGS.TS.Lê Ngoc Thành
} 


\section{2. ĐỐI TƯợNG VÀ PHƯƠNG PHÁP NGHIÊN CÚU}

2.1. Đối tượng: Gồm 38 bệnh nhân nhược cơ có U tuyến ức trong số 68 bệnh nhân được cắt bỏ tuyến ức bằng phẫu thuật nội soi lồng ngực, tại Khoa Phẫu thuật lồng ngực Bệnh viện 103, trong thời gian từ tháng $9 / 2008$ đến $6 / 2012$.

\subsection{Phương pháp nghiên cứu:}

+Chỉ định phẫu thuật:

- Bệnh nhân nhược cơ nhóm I- IIB, có u tuyến ức, tăng sản tuyến ức

- Bệnh nhân nhược cơ tái phát sau mổ mở (đường giữa xương ức)

+Chuẩn bị bệnh nhân:

- Làm các xét nghiệm thường qui cần thiết, chức năng hô hấp.

- Chụp Xquang lồng ngực chuẩn, CT- scanner lồng ngực có bơm khí trung thất.

- Điều trị trước mổ : kháng sinh chống bội nhiễm.

+ Qui trình phẫu thuật :

- Phương pháp vô cảm : gây mê nội khí quản bằng ống nội khí quản 1 nòng (kết hợp bơm khí $\mathrm{CO} 2$ trong mổ) hoặc ống 2 nòng (không cần bơm khí trong mổ)

- Tư thế bệnh nhân : nằm nghiêng $30^{\circ}$.

- Các bước kỹ thuật :

Tuỳ theo vị trí u của tuyến ức mà tiếp cận trung thất qua khoang màng phổi phải hoặc trái

Đặt Trocar: Sử dụng 3 trocars: Trocar đầu tiên cho camera, đặt tại gian sườn $\mathrm{V}$ đường nách giữa,Trocar thứ hai đặt tại gian sườn III đường nách trước, Trocar còn lại đặt tại gian sườn VI đường giữa đòn hoặc đường nách trước.
Dụng cụ nội soi : sử dụng bộ dụng cụ của hãng Karl-Storz

Sau khi phẫu tích giải phóng, khối u sẽ được lấy ra khỏi lồng ngực bằng cách cho vào một túi nilon, kết hợp mở ngực tối thiểu $(3-5 \mathrm{~cm})$ qua một cửa trocar để lấy khối u ra ngoài, trong những trường hợp khối $u$ lớn có thể mở rộng hơn.

Bệnh phẩm được gửi giải phẫu bệnh lý.

Kết thúc phẫu thuật : kiểm tra cầm máu vùng mổ, kiểm tra thông khí phổi, đặt dẫn lưu khoang màng phổi : thường đặt 1 ống (Argyl 32F) dẫn lưu dịch, trong trường hợp cần thiết đặt thêm 1 ống (Argyl-18F) dẫn lưu khí.

Tiến hành nở phổi trước khi rút trocar và đóng ngực.

+ Sau phẫu thuật

- Theo dõi các biến chứng sau phẫu thuật, chụp Xquang lồng ngực kiểm tra và rút dẫn lưu, thu thập kết quả giải phẫu bệnh lý.

- Đánh giá kết quả chia 2 nhóm: tốt (bệnh khỏi; hoặc cải thiện nhiều còn dùng thuốc với liều thấp) và không tốt (bệnh không khỏi cải thiện ít, tái phát).

\section{KẾT QUẢ NGHIÊN CÚU}

\subsection{Một số đặc điểm lâm sàng}

+ Phân bố tuổi: Tuổi bệnh nhân từ 12 đến 69 , trung bình là 33,5, hay gặp nhất lứa tuổi 20-50: 75\%

+Phân bố giới tính: Tỉ lệ bệnh nhân nữ là $68,4 \%$ nhiều hơn so với nam (31,6\%). Tỷ lệ nữ /nam là 2,16

+ Tình trạng nhược cơ: gặp nhiều nhất là nhóm IIA: $63,1 \%$, nhóm IIB $26,3 \%$, nhóm I: $10,6 \%$, có 1 trường hợp tái phát

\subsection{Kết quả phẫu thuật}

3.2.1. Qui trình phẫu thuật

Bảng 3.1: Các bước kỹ thuật

\begin{tabular}{|c|c|c|c|c|}
\hline \multirow{2}{*}{\multicolumn{2}{|c|}{ Qui trình kỹ thuật }} & \multicolumn{2}{|c|}{ Bệnh nhân } & \multirow{2}{*}{$\mathbf{p}$} \\
\hline & & \multirow{2}{*}{$\begin{array}{c}\text { U tuyến ức } \\
n: 38\end{array}$} & \multirow{2}{*}{$\begin{array}{c}\text { Không u } \\
n: 30\end{array}$} & \\
\hline & & & & \\
\hline \multirow{2}{*}{$\begin{array}{l}\text { Gây mê } \\
\text { nội khí quản }\end{array}$} & Đặt ốngl nòng & 1 & 2 & \\
\hline & Đặt ống 2 nòng & $37(97,3 \%)$ & $28(93,3 \%)$ & \multirow{2}{*}{$>0,05$} \\
\hline \multicolumn{2}{|c|}{ Tư thế bệnh nhân: nghiêng $3^{0}$} & 38 & 30 & \\
\hline \multirow{2}{*}{$\begin{array}{l}\text { Vào trung thất qua } \\
\text { KMF }\end{array}$} & Phải & $4(10,6 \%)$ & $0(0,0 \%)$ & \multirow{2}{*}{$<0,01$} \\
\hline & Trái & $34(89,4 \%)$ & $30(100,0 \%)$ & \\
\hline \multirow{2}{*}{$\begin{array}{l}\text { Số trocar } \\
\text { sử dụng }\end{array}$} & 3 & $34(89,4 \%)$ & $28(93,3 \%)$ & \multirow{8}{*}{$>0,05$} \\
\hline & 4 & $4(10,6 \%)$ & 2 & \\
\hline \multirow{6}{*}{$\begin{array}{l}\text { Vị trí } \\
\text { đặt trocar }\end{array}$} & LS 3- nách trước & 38 & 30 & \\
\hline & LS 5- nách trước & & 4 & \\
\hline & LS 5 - nách giũa & 38 & 30 & \\
\hline & LS 6 - giũa đòn & 38 & 30 & \\
\hline & LS6 - nách trước & & 10 & \\
\hline & LS 7 - nách sau & 2 & 2 & \\
\hline
\end{tabular}


Vị trí tiếp cận trung thất để cắt $u$ tuyến ức phụ thuộc vào vị trí của u. Có 34/38 (89,4\%) u lệch về trái được cắt bỏ qua khoang màng phổi trái, chỉ có $10,6 \%$ (4/38) u lệch sang phải được cắt bỏ qua khoang màng phổi phải. Khác với u các trường hợp khác không phải u có thể thực hiện được hoàn toàn qua một bên trái.

\subsubsection{Diễn biến phẫu thuật}

Bảng 3.2: Diễn biến phẫu thuật

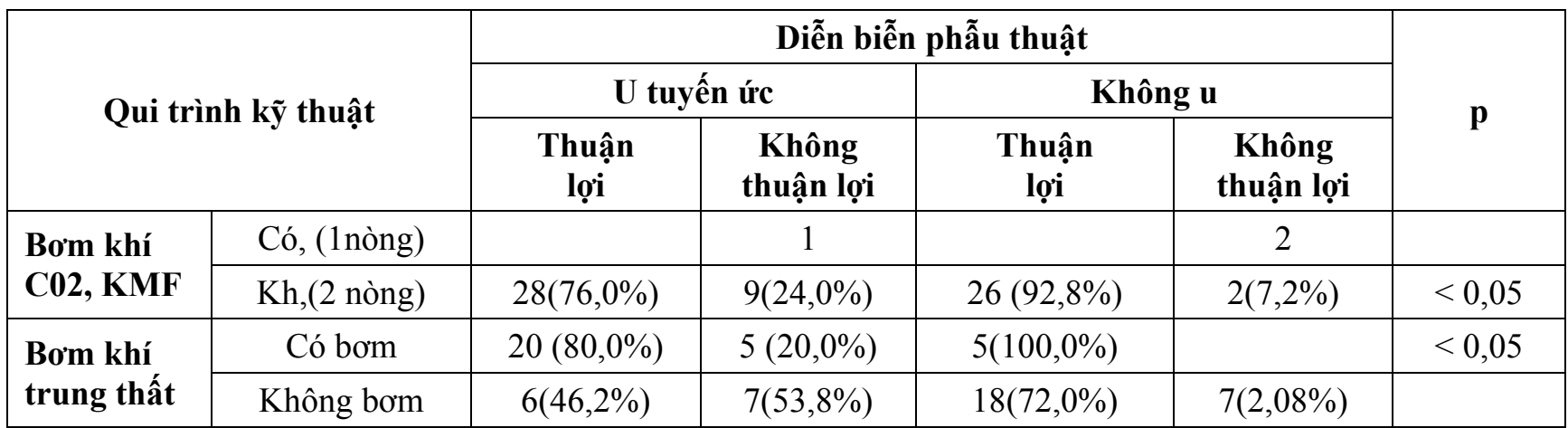

Diễn biến phẫu thuật của nhóm không u thuận lợi hơn nhóm u (92,8\% so với 76,0\%) với p<0,05. Có nghĩa mổ u khó hơn nhóm không u.

Trong nhóm 30 trường hợp có bơm khí trung thất trước mổ: $25 \mathrm{ca} u$ và 5 ca không $\mathrm{u}$ thấy rằng nhờ tác dụng bóc tách của khí giúp quá trình phẫu thuật thuận lợi hơn với cả nhóm u và nhóm không u. Tuy vậy tỷ lệ thuận lợi của u $(80,0 \%)$ thấp hơn $(100,0 \%)$ nhóm không $\mathrm{u}(\mathrm{p}<0,05)$

\subsubsection{Phạm vi can thiệp phẫu thuật}

Bảng 3.3: Phạm vi can thiệp phẫu thuật nội soi lồng ngục

\begin{tabular}{|l|c|c|c|c|c|}
\hline \multirow{2}{*}{ Phạm vi can thiệp } & \multicolumn{4}{|c|}{ Giai đoạn U tuyến ức } & \multirow{2}{*}{} \\
\cline { 2 - 6 } & \multicolumn{2}{|c|}{ Chưa xâm lấn } & Xâm lấn & \\
\cline { 2 - 6 } & I & II & III & IV & \\
\hline Nội soi hoàn toàn & 16 & 14 & 2 & 1 & $33(86,8 \%)$ \\
\hline Chuyển mổ mở & & & 2 & 3 & $5(13,2 \%)$ \\
\hline Cộng & $\mathbf{1 6}$ & $\mathbf{1 4}$ & $\mathbf{4}$ & $\mathbf{4}$ & $\mathbf{3 8}$ \\
\hline
\end{tabular}

Có $86,8 \%$ trường hợp $\mathrm{u}$ được cắt bỏ hoàn toàn bằng nội soi. Trong số này phần lớn $(30 / 33=90,9 \%) \mathrm{u}$ ở giai đoạn I, II, có 3 trường hợp u đã có biểu hiện xâm lấn rộng ra xung quanh (giai đoạn III,IV), vẫn có thể tiến hành nội soi hoàn toàn.

Có $5 / 38(13,2 \%)$ trường hợp phải chuyển sang mổ mở, trong đó có 2 trường hợp $\mathrm{u}$ ở giai đoạn III, quá trình phẫu tích có tai biến tổn thương mạch máu (1 trường hợp rách động mạch phổi, 1 trường hợp rách tĩnh mạch vô danh) gây chảy máu nhiều phải chuyển mổ mở. Còn lại 3 trường hợp $u$ ở giai đoạn IV (xâm lấn màng tim, màng phổi,..) có kích thước lớn hơn $8 \mathrm{~cm}$ không thể cắt được bằng nội soi.

Không có trường hợp nào can thiệp nội soi hỗ trợ, hay dừng lại nội soi chẩn đoán.
+Tai biến, biến chứng trong và sau mổ

- Gặp 2 (5,2\%) trường hợp chảy máu trong mổ: 1 do tổn thương động mạch phổi phải, một do rách tĩnh mạch vô danh.

- Biến chứng trong và sau mổ: tử vong không, suy hô hấp: 2 , tràn dịch khoang màng phổi: 1 .

- Thời gian mổ: trung bình 65 phút (40-180phút), trong đó dưới 60 phút có 19 trường hợp, 60-120 phút có 18 trường hợp, trên 120 phút có 1 trường hợp

- Thời gian hồi sức sau mổ: có 6 bệnh nhân $(15,7 \% \%)$ không qua hồi sức, $28 / 38(73,6 \%)$ bệnh nhân theo dõi từ $12-24 \mathrm{~h}, 4 / 38(10,5 \% \%)$ theo dõi điều trị 48-72h.

+ Thời gian dẫn lưu khoang màng phổi: trung bình 32,6 giờ (24-72 giờ) 
+ Thời gian điều trị sau mổ: trung bình: 7,5 ngày (5-20): dưới 7 ngày có 22 bệnh nhân, $7-15$ ngày có 14 bệnh nhân, trên 15 ngày có 2 bệnh nhân.

+ Tỷ lệ kết quả tốt sau mổ: 6 tháng là $84,0 \%$, sau một năm là $88,9 \%$ tương đương tỷ lệ tốt $85,7 \%$ và $87,8 \%$ của nhóm mổ mở.

\section{BÀN LUẬN}

\section{+ Chỉ định phẫu thuật :}

Điều trị ngoại khoa bệnh nhược cơ bằng phẫu thuật cắt bỏ tuyến ức có thể tiến hành ở các lứa tuổi, trong cả 2 giới. Kết quả nghiên cứu của chúng tôi gặp các bệnh nhân nhược cơ ở tất cả các lứa tuổi từ 12 đến 69. Tuổi trung bình là 33,5 lứa tuổi hay gặp nhất là từ 20-50 tuổi. kết quả này cũng phù hợp với nhận xét ở một số công trình nghiên cứu trước đó về điều trị ngoại khoa băng cắt bỏ tuyến ức theo phương pháp mổ mở kinh điển: Nguyễn Văn Thành(1988), Mai Văn Viện (2004)(2009)[2],. Điều này khẳng định rằng phẫu thuật nội soi lồng ngực có thể áp dụng được cho các bệnh nhân nhược cơ tuổi từ 12 đến 69 tuổi.

Tỷ lệ mắc bệnh của nữ/nam trong nghiên cứu của chúng tôi là 2,16. Nhóm u là 2,3 tương đương Drachman D.B (1994)[2] là 1,5. Như vậy sự phân bố giới trong nghiên cứu này tương đương như trong mổ mở.

Tình trạng nhược cơ: gặp 3 nhóm: I, IIA, IIB, trong đó chủ yếu là nhóm IIA $(63,1 \%)$. Tỷ lệ này tương đương kết quả của các công trình nghiên cứu về điều trị ngoại khoa bệnh nhược cơ theo các phương pháp kinh điển trước đây. Đặc biệt chúng tôi có chỉ định cho 2 trường hợp nhược cơ nhóm IIA tái phát sau phẫu thuật cắt tuyến ức bằng đường mở xương ức, 1 trường hợp $u$ và 1 trường hợp tăng sản tuyến kết quả mổ thuận lợi và tốt.

Tổn thương mô bệnh học: u: 38 trường hợp, tăng sản tuyến: 23 trường hợp, tồn tại tuyến ức là 7 .

Trong số 38 trường hợp $\mathrm{u}$ trừ 3 trường hợp $\mathrm{u}$ to, ở giai đoạn IV (tức là có xâm lấn màng tim, màng phổi), và hai trường hợp chảy máu phải chuyển mổ mở còn lại 33 ca u từ giai đoạn I đến giai đoạn III (theo phân loại của Masaoka) đều có thể cắt được hoàn toàn bằng nội soi. Tuy nhiên u ở giai đoạn III, quá trình phẫu tích khó khăn hơn.

Nhu vậy, phẫu thuật nội soi lồng ngực có thể chỉ định cắt bỏ tuyến úc điều trị bệnh nhược co với các bệnh nhân tì̀ nhóm I đến nhóm IIB, có u hoạc không có u tuyến ức, nhược cơ tái phát, tuổi tù̀ 12- 69, cả hai giới nam và nũ.

+ Phương pháp vô cảm: Do tính chất của bệnh, để hạn chế biến chứng suy hô hấp trong và sau mổ, khi mổ cắt tuyến ức qua đường mở dọc giữa xương ức các tác giả thường được thực hiện dưới phương pháp vô cảm là châm tê. Vì vậy khi ứng dụng phẫu thuật nội soi cắt tuyến ức, vấn đề đặt ra là liệu trong và sau gây mê tình trạng nhược cơ của bệnh nhân sẽ diễn biến như ra sao ? tỷ lệ suy hô hấp sau mổ thế nào?

Thực tế cho thấy sự ảnh hưởng của gây mê là không đáng lo ngại. Vấn đề đặt ra là nên đặt ống nội khí quản một nòng hay đặt ống hai nòng. Số liệu bảng 1 cho thấy đại đa số bệnh nhân $(97,3 \%$ nhóm u, $93,3 \%$ nhóm không $u$ ) được đặt ống nội khí quản hai nòng, chỉ có khoảng 5,0\% là đặt ống một nòng.

+ Tư thế bệnh nhân trong mổ: ở 68 bệnh nhân cho thấy: tư thế nằm nghiêng một góc $30^{\circ}$, có kê gối phía sau lưng, vai. Tuy nhiên theo Yim A(1996) đề xuất là có thể đặt nghiêng bệnh nhân $90^{\circ}$ [4]

\section{+ Đường tiếp cận trung thất:}

Tuỳ theo kinh nghiệm, đặc điểm tổn thương giải phẫu bệnh tuyến ức mà các tác giả có sự lựa chọn khác nhau. Với Yim.A (1996), tác giả thường chọn đường tiếp cận trung thất qua khoang màng phổi phải. Một số tác giả Châu Âu lại lựa chọn đường tiếp cận qua khoang màng phổi trái [6],[7]. Trong số 68 trường hợp của chúng tôi có tới 94,1\% (64/68) tiếp cận trung thất qua khoang màng phổi trái, chỉ có 4/68 (5,9\%) phẫu thuật qua khoang màng phổi phải. Trong nhóm $\mathrm{u}$ có tới $10,5 \%$ trường hợp u lệch sang bên phải và được cắt bỏ u qua khoang màng phổi phải, trong khi đó ở nhóm không u 100\% trường hợp có thể cắt bỏ được toàn bộ tuyến ức qua khoang màng phổi trái.

Lựa chọn đường tiếp cận trung thất qua khoang màng phổi bên phải hay bên trái chủ yếu là dựa vào đặc điểm tổn thương giải phẫu bệnh của tuyến ức cụ thể là vị trí của u tuyển ức trên phim chụp cắt lớp vi tính lồng ngực. Chúng tôi chưa nhận thấy có sự khác biệt gì rõ ràng khi phẫu thuật qua bên phải hay trái.

\section{+ Số trocars sử dụng :}

Cũng như một số tác giả: để can thiệp cắt bỏ tuyến ức bằng phẫu thuật nội soi thông thường phải cần đến 3 đường vào cho 3 trocar trong đó một dành cho camera, còn lại 2 trocar cho dụng cụ phẫu thuật. Trong những trường hợp cần thiết người ta có thể dùng thêm một trocar thứ tư hoặc thứ năm.

Kết quả của chúng tôi (bảng 3.1) cho thấy: đại đa số bệnh nhân nhóm u $(89,4 \%)$ cũng như nhóm không u $(93,3 \%)$ chỉ dùng 3 trocar, chỉ có 6 trường hợp: 4 ở nhóm $\mathrm{u}$ và 2 ở nhóm không u có sử dụng đến 4 trocars. Với số lượng trocar như vậy chúng tôi có thể thao tác cắt tuyến, $\mathrm{u}$ tuyến ức thuận lợi. Những trường hợp phải sử dụng đến trocar thứ tư là do bệnh nhân 
béo, có những dải mỡ rất dày phía ngoài màng tim gây cản trở cho khả năng quan sát cũng như phẫu tích.

\section{+ Vị trí đặt Trocars:}

Vị trí mà các tác giả hay dùng là: gian sườn 3 đường nách giữa, gian sườn 5 đường nách sau và gian sườn 6 đường nách trước.[5],[6],[8].

Trong nghiên cứu của chúng tôi có 3 vị trí thường được sử dụng là: liên sườn 3 đường nách trước (100\%), vị trí đặt camera ở liên sườn 5 đường nách giữa $(100,0 \%)$ và liên sườn 6 đường giữa đòn là $100,0 \%$. Với những vị trí như vậy cuộc mổ có thể thực hiện được một cách thuận lợi.

+ Diễn biến và phạm vi can thiệp phẫu thuật: Trong số 68 trường hợp phẫu thuật nội soi lồng ngực có tới $83,3 \%$ số cuộc mổ được tiến hành một cách bình thường và thuận lợi, trong số đó phải kề đến có gần nửa số trường hợp $(30 / 68)$ có bơm khí trung thất ngay trước mổ. Dưới tác dụng bóc tách của không khí sẽ giúp cho phẫu thuật viên xác định và phẫu thuật vào trung thất tốt hơn, đặc biệt là với những trường hợp u tuyến ức. Kết quả này cũng phù hợp với những nhận xét của một số tác giả Ý năm 1996 [6]. Như vậy, việc bơm khí trung thất có thể áp dụng rộng rãi hơn vì đây là một thủ thuật tương đối đơn giản, dễ thực hiện, không tốn kém.[7]

Nguyên tắc phẫu thuật là phải lấy triệt để tuyến ức. Trong phẫu thuật nội soi lồng ngực cũng vậy, kết quả của nhiều công trình nghiên cứu trong và ngoài nước đã cho thấy giá trị của việc nội soi lồng ngực giúp cho phẫu thuật viên có khả năng quan sát rộng rãi hơn, giúp đánh giá được tình trạng tại chỗ cũng như xung quanh, đặc biệt là những trường hợp có $\mathrm{u}$ tuyến ức dính vào xung quanh . Kết quả nghiên cứu cho thấy: với 68 trường hợp phẫu thuật nội soi lồng ngực chúng tôi có thể cắt toàn bộ tuyến ức, u tuyến ức một cách thuận lợi.

Đặc biệt là trong số 38 trường hợp u tuyến ức có 33 trường hợp $(86,6 \%) \mathrm{u}$ ở giai đoạn I đến giai đoạn III theo Masaoka chúng tôi đã cắt bỏ hoàn toàn bằng nội soi an toàn. Ngoài 2 trường hợp có tai biến tổn thương mạch máu, còn lại 3 trường hợp u phải chuyển mổ mở, đó là 1 trường hợp $\mathrm{u}$ tái phát, 2 trường hợp khác u đã xâm lấn nhiều vào cả màng tim ( giai đoạn IV theo Masaoka).

Kết quả này cho thấy qua nội soi lồng ngực chúng ta có thể can thiệp phẫu thuật cắt tuyến ức nói chung, u tuyến ức nói riêng một cách triệt để.[1],[3]

\section{+ Về tai biến và biến chứng của phẫu thuật:}

Không có trường hợp nào tử vong trong và sau mổ. Có 2 trường hợp tổn thương mạch máu, dù đã tích cực cầm máu bằng kẹp Clip nhưng do tổn thương phức tạp (1 trường hợp rách động mạch phổi trái, 1 trường hợp rách tĩnh mạch vô danh) nên cầm máu qua nội soi không có hiệu quả phải chuyển mổ mở. Như vậy để hạn chế tai biến này cần xác định được tính chất xâm lấn của $u$ trước mổ bằng chụp cắt lớp vi tính lồng ngực có bơm khí trung thất và không nên chỉ định mổ khi u có xâm lấn nhiều (giai đoạn III và IV).

Về biến chứng của phẫu thuật: gặp 4/68 trường hợp chiếm $5,8 \%$ có biểu hiện suy thở sau mổ cần thông khí hỗ trợ. Trong số này phần lớn đều trở lại bình thường trong vòng 24 giờ đầu sau mổ.

Cần phải nói rằng nhờ có phẫu thuật nội soi, không phải mở xương ức nên đã hạn chế đau đớn giúp người bệnh có thể tự thở tốt hơn. Biến chứng suy thở sau mổ $5,8 \%$ thấp hơn rõ rệt so với mổ mở là 20-30\%. Đây cũng là vấn đề rất quan trọng với bệnh nhân nhược cơ. Chúng tôi có gặp 1 trường hợp tràn dịch khoang màng phổi sau mổ do tai biến tổn thương mạch máu phải chuyển mổ mở. Có 2 trường hợp đau thần kinh liên sườn sau mổ vào tháng đầu sau đó ổn định. Hai trường hợp có rò dịch qua một trong 3 lỗ mở thành ngực để đặt trocar. Không có trường hợp nào liệt thần kinh hoành như thông báo của một số tác giả.

+ Về thời gian phẫu thuật: thời gian mổ kéo dài từ 40 phút đến 180 phút trung bình 65 phút, trong đó chủ yếu $(80,0 \%)$ trong khoảng 60-120 phút, có khoảng gần $20 \%$ bệnh nhân thời gian mổ dưới 1 giờ. Có duy nhất một trường hợp kéo dài đến 3 giờ, đây là trường hợp mổ đầu tiên do chưa có kinh nghiệm từ việc đặt tư thế bệnh nhân, đường tiếp cận khoang màng phổi, mốc xác định để đi vào trung thất,...nên thời gian mổ đã phải kéo dài như vậy. Từ các trường hợp thứ hai trở đi chúng tôi đã rút được kinh nghiệm vì thế thời gian mổ rút ngắn một cách rõ rệt, kể cả là những trường hợp u có xâm lấn ra xung quanh nhưng thời gian tối đa chỉ còn là hai giờ.

+ Thời gian điều trị hồi sức tích cực: trước đây với phẫu thuật cắt tuyến ức qua đường mở dọc giữa xương ức thì hầu như tất cả các trường hợp đều được điều trị hậu phẫu tại khoa hồi sức tích cực. Trong số đó có nhiều trường hợp phải điều trị dài ngày tại hồi sức vì biến chứng suy hô hấp sau mổ, có những trường hợp kéo dài hàng tháng, đến hàng năm, tạo ra 
một tâm lý nặng nề cho bệnh nhân và người nhà bệnh nhân. Với 38 bệnh nhân nhược cơ có u tuyến ức được phẫu thuật nội soi cho thấy có $6 / 38(15,7 \%)$ bệnh nhân được chuyển về hậu phẫu tại khoa ngay sau mổ không qua hồi sức.

Số còn lại phải qua hồi sức để theo dõi trong vòng 24 giờ đầu sau mổ. Đây là ưu điểm của phẫu thuật nội soi lồng ngực cắt bỏ tuyến ức nói chung, u tuyến ức nói riêng điều trị bệnh nhược cơ. Nhờ tránh phải đục xương ức, bệnh nhân ít đau, giúp cho khả năng tự thở của bệnh nhân sau mổ tốt hơn, hạn chế được biến chứng suy hô hấp sau mổ.

+ Thời gian điều trị sau mổ: Không kể thời gian nằm viện trước mổ thì thời gian điều trị trung bình sau mổ là 7,5 (5-20 ngày), cao hơn so với kết quả 5 ngày của một số tác giả. Giải thích cho sự khác nhau này phải chăng là liên quan đến chỉ định: nếu mổ những bệnh nhân nhược cơ nhẹ thì thời gian sau mổ sẽ ngắn hơn. Tuy nhiên so với trước đây thì thời gian trung bình như vậy đã được rút ngắn một cách rõ rệt. Đó là một ưu điểm về ứng dụng nội soi lồng ngực trong phẫu thuật cắt bỏ tuyến ức điều trị bệnh nhược cơ.

+Tỷ lệ kết quả tốt ở giai đoạn sớm sau mổ.

Theo dõi, kiểm tra đánh giá kết quả sớm ở 45 bệnh nhân sau mổ trên 6 tháng nhận thấy kết quả tốt giữa nhóm $u$ và không u là tương đương là $84,0 \%, 35$ bệnh nhân sau 1 năm là $88,9 \%$, tương đương với kết quả tốt $85,7 \%$ và $87,8 \%$ của phương pháp cắt tuyến ức qua đường mở giữa xương ức. Tuy số lượng bệnh nhân chưa nhiều nhưng kết quả bước đầu như vậy gợi mở một hướng đi mới cho điều trị ngoại khoa bệnh nhược cơ.

\section{KẾT LUẬN}

Với kết quả nghiên cưu ưng dụng nọi soi lồng ngục trong cắt bỏ u tuyến úcc điều trị bệnh nhược co ơ 68 bệnh tại Bệnh viện 103 trong thời gian tù 9/20086/2012, chúng tôi bước đầu rút ra một số kết luận sau:

Phẫu thuật nội soi lồng ngực là phuoong pháp điều trị an toàn, hiệu quả

- Có thể tiến hành trên bệnh nhân nhược co tù nhóm I-IIB, có hoặc không có u tuyến ức, tuổi: 12- 69, cả 2 giới nam và nũu,

- Không có tư vong phẫu thuật, tai biến, biến chưng thấp.

- Uu điểm: tổn thưong thành ngục it, it đau, thời gian điều trị sau mổ ngắn, thẩm mỹ.
- Kết quả tốt ở giai đoạn sớm sau mổ 84,0\%, sau Inăm là $88,9 \%$ tuoong đương với $85,7 \%$ và $87,8 \%$ của phẫu thuât mổ mở qua xurơng úc.

\section{TÀI LIỆU THAM KHẢO}

1. Nguyễn Công Minh (2008), "Phẫu thuật nội soi cắt tuyến hung điều trị bệnh nhược cơ" Thông tin khoa hoc, Bệnh viện Chọ Rãy.

2. Mai Văn Viện (2004) "Nghiên cứu một số đặc điểm lâm sàng, $X$ quang và mô bệnh học tuyến ức liên quan đến kết quả điều trị ngoại khoa bệnh nhược cơ", Luận án tiến sỹ Y học, Học viện quân $Y$.

3. Mai Văn Viện, Phạm Vinh Quang (2009), Kết quả ứng dụng phẫu thuật nội soi lồng ngực trong cắt bỏ tuyến ức điều trị bệnh nhược cơ, Tạp chí Y học thực hành, số 690-691: 18-24.

4. Phạm Vinh Quang, Mai Văn Viện (2010), Phẫu thuật tuyến ức điều trị bệnh nhược cơ, Sách chuyên khảo, Nhà xuất bản $\mathrm{Y}$ học

5. Mack M., Landreneau R.J., Yim A.P., Hazelrigg S.R., Scruggs G (1996) "Results of video-assisted thymectomy in patients with myasthenia gravis", JThorac Cardiovasc Surg, 112 (5), pp. 1352-60.

6. Mack M., Scruggs G (1998), "Video-assited thoracic surgery thymecthomy for myasthenia gravis", Chest surg clin north america, 8 (4), pp. 809-25.

7. Mineo TC, PompeoE., Ambrogi V, Sabato AF, Bernardig (1996) "Adjuvantpneumomediastinumin thoracoscopic thymectomy for Myasthenia gravis" Ann Thoracsurg 62, pp.853-9

8. Rea F., Bortolottil, Firardir., et al (2003), "Thoracoscopic thymectomy with "Da Vinci" Surgical System in patient with Myasthenia gravis", Interact Cardiovasthoracsurg, PP. 70 -72.

9. Yoshino I., Hashizume M., Shimada M., Tomikawa M., Tomiyasu M., Suemitsu R, Sugimachi K(2001), "Thoracoscopic thymectomy with the da Vinci computerenhanced surgical system", J thorac Cardiovasc Surg, 122(4), pp. 783-5. 